\title{
Continuous source of care among young underserved children: associated characteristics and use of recommended parenting practices.
}

\author{
Esther K Chung \\ Department of Pediatrics, Alfred I. duPont Hospital for Children \\ Leny Mathew \\ Department of Pediatrics, Alfred I. duPont Hospital for Children \\ Kelly F McCollum \\ Department of Pediatrics, Alfred I. duPont Hospital for Children \\ Irma T Elo

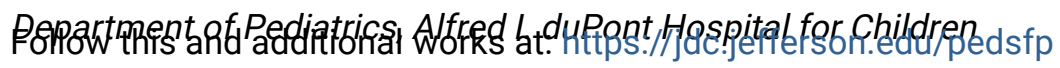 \\ PpiferftGellianics and Medical Ethics Commons, and the Pediatrics Commons

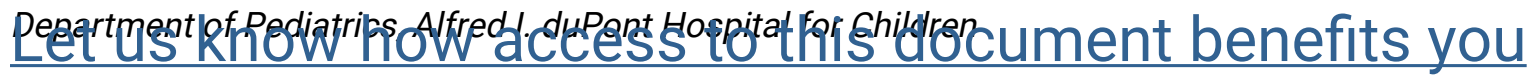

\section{Recommended Citation}

Chung, Esther K; Mathew, Leny; McCollum, Kelly F; Elo, Irma T; and Culhane, Jennifer F, "Continuous source of care among young underserved children: associated characteristics and use of recommended parenting practices." (2008). Department of Pediatrics Faculty Papers.

Paper 46.

https://jdc.jefferson.edu/pedsfp/46

This Article is brought to you for free and open access by the Jefferson Digital Commons. The Jefferson Digital Commons is a service of Thomas Jefferson University's Center for Teaching and Learning (CTL). The Commons is a showcase for Jefferson books and journals, peer-reviewed scholarly publications, unique historical collections from the University archives, and teaching tools. The Jefferson Digital Commons allows researchers and interested readers anywhere in the world to learn about and keep up to date with Jefferson scholarship. This article has been accepted for inclusion in Department of Pediatrics Faculty Papers by an authorized administrator of the Jefferson Digital Commons. For more information, please contact: JeffersonDigitalCommons@jefferson.edu. 
Continuous source of care among young underserved children: Associated characteristics and use of recommended parenting practices.

Esther K. Chung, MD, MPH; Leny Mathew, MS; Kelly F. McCollum, MPH; Irma T. Elo, $\mathrm{PhD}, \mathrm{MPA}$; and Jennifer F. Culhane, PhD, MPH

As published in: Ambulatory Pediatrics, 2008. 8(1), 36-42.

DOI: 10.1016/j.ambp.2007.08.005

(C) 2008 Ambulatory Pediatric Association. 


\section{Continuous Source of Care among Young Underserved Children:} Associated Characteristics and Use of Recommended Parenting Practices

Esther K. Chung, MD, MPH; Leny Mathew, MS; Kelly F. McCollum, MPH; Irma T. Elo, PhD, MPA; and Jennifer F. Culhane, PhD, MPH

From the Department of Pediatrics, Alfred I. duPont Hospital for Children, Wilmington, DE and Jefferson Medical College, Philadelphia, PA (Dr. Chung); the Department of Obstetrics and Gynecology, Drexel University College of Medicine, Philadelphia, PA (Ms. McCollum, Mr.

Mathew, Dr. Culhane); and the Department of Sociology, University of Pennsylvania, Philadelphia, PA (Dr. Elo).

Corresponding author: Esther K. Chung, MD, MPH; Associate Professor of Pediatrics, Jefferson Pediatrics/duPont Children's Health Program, 833 Chestnut Street, Suite 300, Philadelphia, PA 19107. Phone: 215-955-9460. Fax: 215-503-4429. Email: echung@nemours.org.

Abstract Word Count: 250 words

Manuscript Word Count: 3454 words

Running Title: Continuous Source of Care Among Young Underserved Children

This research was presented at the Pediatric Academic Societies Meeting in Washington, DC, May 16, 2005, and funded in part by grants from the Centers for Disease Control and Prevention, \#TS-286-14/14 (Co-PI: Dr. Jennifer Culhane), and the National Institute of Child Health and Human Development, \#1-RO1-HD36462-01A1 (Co-PIs: Drs. Jennifer Culhane and Irma Elo). There are no potential conflicts of interests or corporate sponsorships.

Key words: usual source of care; maternal and child health; medical home; parenting; primary care 


\section{ABSTRACT}

Objectives: 1) Assess sociodemographic and health characteristics associated with having a continuous source of care (CSOC) among young children, and 2) determine the relationship between having a CSOC and use of parenting practices.

Design/Methods: Prospective, community-based survey of women with prenatal care at Philadelphia community health centers. We conducted surveys at the first prenatal visit and at a mean age \pm standard deviation (SD) of $3 \pm 1,11 \pm 1$, and $24 \pm 2$ months postpartum, obtaining information on sociodemographic and health characteristics, child's health care provider, and six parenting practices. Group differences were tested between those with and without CSOC using the Chi-square test for categorical variables, and the student's t test for continuous variables. Logistic regression analysis was conducted to adjust for potential confounding variables. Results: Our sample consisted of 894 mostly young, African American, single women and their children. In the adjusted analysis, mothers of children with when compared to those without a CSOC were more likely to have a high school education or less, be born in the US, have a postpartum check-up, have stable child health insurance, and initiate care for their child at a site other than a community-based health center. Use of parenting practices was similar for children with and without a CSOC.

Conclusions: Maternal nativity, postpartum care, child health insurance, and initial site of infant care were associated with a CSOC, but infant health characteristics were not. Use of parenting practices did not differ for those with and without a CSOC. 


\section{BACKGROUND}

One basic tenet of primary care is to ensure that all people have a usual source of care consisting of a single or group of healthcare providers. ${ }^{1}$ This concept is central to "the medical home," defined by the American Academy of Pediatrics (AAP) as a place promoting access and coordinating care. $^{2}$ As part of a medical home, pediatricians promote longitudinality, the presence and use of a regular source of care over time, and continuity, the sequence of visits in which there is a mechanism for information transfer. ${ }^{1}$ Another basic tenet of pediatric primary care is that the usual source of care, be it a single provider or group, offers anticipatory guidance to the family and promotes the use of recommended parenting practices, such as breastfeeding and injury prevention measures. ${ }^{3-5}$

Having a continuous source of care (CSOC) resonates with healthcare providers, yet measuring it and its effects is not straightforward. This difficulty is evident in the lack of uniformity and distinction in what is measured. Some investigators measure having "a usual source of care," defined as care received in emergency rooms on one extreme and in private offices on the other. ${ }^{6-8}$ Other investigators assess "continuity of care" based on self report or based on one of 32 continuity-of-care indices, which have great deal of heterogeneity and measure different aspects of care. ${ }^{9-13}$

Despite definition and measurement variations and overlap, there is evidence that having a usual source of care and having continuity of care are associated with health benefits.

Numerous studies report beneficial effects of having a usual source of care, including higher rates of preventative care use, ${ }^{7,8,14}$ fewer acute care visits and hospitalizations, and receipt of symptom-based care among adolescents. ${ }^{15}$ Continuity of care -- self-reported, or with a single site or provider - has been associated with increased patient satisfaction, ${ }^{9,16-19}$ better perceived 
quality of care, ${ }^{20}$ receipt of preventative care, ${ }^{21}$ timely measles-mumps-rubella vaccination, ${ }^{22}$ increased likelihood of taking medications correctly and having problems identified, ${ }^{17}$ decreased emergency department use, ${ }^{11,12,23-25}$ and lower likelihood of hospitalization ${ }^{26}$ and overall health care costs. $^{27-29}$

Few investigators have determined sociodemographic and health characteristics associated with having a usual source of care or continuity of care. Reported risk factors for lacking continuity include living in low-income neighborhoods, maternal young age, single marital status, residential mobility, and inadequate prenatal care. ${ }^{30}$ Despite a general desire for a continuous source of care, maintaining one may be difficult for patients, particularly if they experience employment, residence and health insurance changes.

There are no known studies, to date, that assess the relationship between having a usual or continuous source of care and the use of recommended parenting practices. Previous studies, however, have shown that physician recommendations strongly impact parental use of a number of recommended early childhood practices, including use of the back sleep position for infants, exclusive breastfeeding at 4 weeks of life, breastfeeding duration, and reading to young children. ${ }^{31-35}$

To promote the medical home and to encourage adoption of a CSOC for children, it is important to understand maternal and child sociodemographic and health characteristics associated with having a CSOC, particularly among those at greatest risk for lacking continuity. We conducted this study to do the following: 1) to assess sociodemographic and health characteristics associated with having a CSOC among low-income women and their children who report having a usual source of care, and 2) to determine the relationship between having a CSOC and use of recommended parenting practices in early childhood. Considering the 
previously reported benefits of continuity, we hypothesized that those with a CSOC, when compared with those without a CSOC, would be more likely to use recommended parenting practices.

\section{METHODS}

This research is a sample of a larger prospective, community-based cohort study on maternal stress, birth outcomes and infant health. As part of the larger study, this research was approved by the Institutional Review Boards at Thomas Jefferson University and the University of Pennsylvania. The overall cohort consisted of women receiving prenatal care from February 2000 to November 2002 at Philadelphia community-based health centers, described previously ${ }^{36}$ and consisting of Federally Qualified Health Center Look Alikes (FQHC-LAs) and FQHCs. The enrollment criteria included having an intrauterine pregnancy and the ability to speak English or Spanish. Of 1,984 women with live births in the overall cohort, 1,670 (84\%) women lived with their child and were interviewed at least once during the postpartum period, $4 \%$ had moved too far away, 5\% refused interviews, $1 \%$ were excluded after enrollment for reasons such as child death, and $6 \%$ were lost to follow-up (Figure 1). When compared with all Philadelphia women who gave birth in 2001, these women were slightly younger, less educated, and economically more disadvantaged. Details of our cohort study have been described previously. ${ }^{36,37}$

This investigation utilized data from four surveys; the first was administered to women at their first prenatal care visit. Three additional face-to-face, postpartum surveys were conducted at their targeted times at a mean \pm standard deviation of $3 \pm 1$ (postpartum survey $1 ;$ PP1), $11 \pm 1$ (PP2), and $24 \pm 2$ months (PP3) in the participants' homes. The structured surveys were conducted in English and Spanish by trained, female interviewers using standardized 
questionnaires. At PP1, we assessed sociodemographic factors and behavioral practices. The postpartum surveys contained information about the child's health, including use of child health services and six recommended parenting practices.

Figure 1 is a flow diagram of study participants. Of the 1,670 women living with their child, 947 (57\%) completed all four (1 prenatal and 3 postpartum) surveys. The remaining 724 (43\%) completed the prenatal survey and some (one or two) of the postpartum surveys. When compared to those completing all postpartum surveys, those completing some were more likely to be foreign-born and to have their surveys conducted in Spanish. These 2 groups did not differ for the following characteristics: maternal age, education, race/ethnicity, marital status, annual household income, insurance status, car access; or child gender, birthweight, gestational age, or birth order (data not shown). Of the 947 women who completed all surveys, 53 (6\%) women were dropped due to missing information on their child's source of care. Our final sample consisted of 894 mother-child dyads with a usual source of care at each postpartum survey.

\section{Study Variables}

Having a CSOC was defined as having the same site of care for all 3 postpartum surveys based on the question, "Where do you take [child] for well-baby care?" At each of the postpartum surveys, mothers were asked for their child's health care provider's name and the practice name, affiliated hospital, address and telephone number. Prior to data analysis, responses to this question at each of the visits were reviewed in detail, subject-by-subject, to determine if a CSOC was maintained for the entire study period.

We considered the following sociodemographic and health-related characteristics, outlined by timing of collection, as factors that may contribute to having a CSOC and as 
potential confounding variables: 1) antepartum survey data: maternal age, education, race/ethnicity, Spanish-speaking prenatal care site, language of survey, nativity, marital status, insurance status, income, and child's birth order; 2) PP1 data: maternal access to and ownership of a car (not asked at PP2 or PP3), having a regular source of pre-pregnancy care, having a main prenatal care provider, being told that the pregnancy was high-risk, and having a check-up at 6 weeks postpartum; and child's site of initial hospitalization (intensive care versus newborn nursery), special needs, and site of initial well-child care (community-based health center, private practice, and hospital-based clinic - defined elsewhere ${ }^{36}$ ); 3) PP3 data: child's age; 4) data from PP1 to PP3 - residence stability (stable residence $=0$ moves) and child health insurance stability (stable insurance $=0$ changes in type [i.e., none, Medicaid, via work or selfpay]). The child's sex, birthweight, and gestational age were obtained from linked, birth certificate data.

We studied 6 well-accepted and recommended parenting practices that were defined by the following questions: 1) Breastfeeding for 1 month or longer was based on the question, "How long did you breastfeed?" that was asked at PP1 (mean age $3 \pm 1$ mos); 2) Use of the back sleep position at PP1 was based on the response of "back" to the question, "In what position do you usually put [child] down to sleep?" Other potential answers were "side" and "stomach." This question resembles the one used in surveys that assess national rates of back sleep position use, ${ }^{38}$ 3) Reading three times or more per week at PP2 (mean age \pm SD: $11 \pm 1$ mos) was based on, "How often do you get a chance to read stories to or look at picture books with [child]?" The response of "about three times a week" or "every day" qualified as "reading three or more times per week," while "never," "several times a year," and "once a week" were classified as reading less than three times per week. This question and answer categorization is similar to that used in 
the National Household Education Survey, which is used to report national rates of reading; ${ }^{39,40}$ 4) Not using corporal punishment at PP2 was based on a response of "0" to, "About how many times, if any, have you had to spank your (11 1 mos old $)$ child in the past week?" 5) Use of stair gates at PP3 (mean age \pm SD: $24 \pm 2$ mos) was based on an affirmative response to "There are gates on stairs in your house when [child] is at home;" 6) Use of electric outlet covers at PP3 was based on an affirmative response to, "There are protectors in the electrical sockets in your house." The six parenting practices that we studied are well-accepted recommendations by national child health experts, including several task forces and committees of the American Academy of Pediatrics. ${ }^{4,34,41-46}$ These recommendations have been shown to be important in the health and development of young children. While use of "spanking" is controversial for some, most experts would agree that corporal punishment use in infancy, as measured in our study, is not recommended.

\section{Statistical Analyses}

Group differences were tested between those with and those without a CSOC using the Chisquare test for categorical variables. The Fisher's exact test was used if the expected values in the cells were less than 5 . We also tested group differences between those in our final sample and those who were not included because they did not complete all of the postpartum surveys (see above). For the dependent variable, CSOC, we conducted a logistic regression analysis to adjust for potential confounding variables and to derive maximum likelihood estimates of combined relative odds with $95 \%$ confidence intervals.

Risk factors and confounders for potential inclusion in our final regression model were identified a priori based on our literature review and theoretical considerations. To obtain our 
final model, we included all variables from our literature review, assessed if the model fit with these variables included, and subsequently dropped all variables not contributing to the overall model fit. The final logistic regression adjusted for maternal age, education, race/ethnicity, marital status, language of survey, nativity, residential stability, having a postpartum check-up, having access to a car; and the child's birth order, health insurance, age at PP3, and site of initial well child care. Alpha was set at 0.05 (two-sided), and Stata 8.2 was used for all analyses. ${ }^{47}$ Since the prevalence of CSOC was relatively high (64\%), using a logistic regression model could produce inflated odds ratios (ORs), and this would be problematic if the ORs were interpreted as relative risks. To account for this possibility, we also modeled the data using a Poisson regression approach with robust standard errors. It was found that the relative risks generated by the Poisson model were slightly less than the ORs provided by the logistic regression model. Also, all the terms that were significant in the logistic model were significant at approximately the same level in the Poisson model. Since we were more interested in associations rather than the magnitude of the OR or relative risks, we present the data from the logistic regression model. The Hosmer-Lemeshow goodness-of-fit Chi-square statistic was calculated for the model to assess the logistic regression model fit. ${ }^{48}$

\section{RESULTS}

The sociodemographic and health characteristics for our overall sample are shown in column 2 of Table 1. The women in our sample were mostly low-income, young, African American, uninsured, and single. Ten percent of children had low birthweight $(<2500$ grams), comparable to national percentages of $7.6 \%$ overall and $13 \%$ for African Americans; $11 \%$ were preterm ( $<37$ weeks gestation) with national percentages being $11.6 \%$ overall $;{ }^{49}$ and $14 \%$ were 
hospitalized in an intensive care setting. For their initial well-child care site, approximately $37 \%$ of children attended community-based health centers at PP1, while the remainder went to private practices and hospital-based clinics. The majority of the women (64\%) in our sample identified a continuous source of care (see Figure 1). Table 1, columns 3 through 5, shows the unadjusted comparison of those with and without a CSOC. The two groups differed with respect to maternal education, nativity, residential stability, receipt of a postpartum check-up, child health insurance stability, and site of initial well-child care.

Overall, as shown in Table 2, only $26 \%$ of women breastfed for 1 month or longer, which is less than the $44 \%$ of African American mothers and much less than the $63 \%$ of mothers overall who reported breastfeeding at 1 month in a national sample. ${ }^{50}$ Just over half of our sample reported using the back sleep position, comparable to the $50 \%$ to $75 \%$ prevalence found in a national study. ${ }^{51}$ Only $57 \%$ of mothers reported reading to their child (at a mean age of 11 mos) at least three times per week, which is substantially less than the $76 \%$ of mothers in a national survey who read to their 10 - to 18 -month-old children at least three times per week. ${ }^{32}$ Although the majority reported not using corporal punishment, as many as $14 \%$ reported corporal punishment use at PP2. Just over half of mothers reported using electric outlet covers, and only one-fifth used stair gates. Comparable national data were not available for the latter 3 parenting practices. We compared each of the 6 parenting practices for mothers reporting CSOC with those without CSOC, and there were no statistically significant differences (Table 2). In the multivariate analysis, children of women with a high school education or less, US nativity, receipt of a postpartum check-up, stable child health insurance, and site of initial well-child care were more likely to have a CSOC than were their counterparts (Table 3). The 
Hosmer-Lemeshow goodness-of-fit Chi-square statistic was 4.77 with a p-value of 0.78 , showing that the model fits the data well.

\section{DISCUSSION}

In this study, we explored the concept of having a continuous source of care or having the same primary care office or group of healthcare providers throughout early childhood. We determined which maternal and child sociodemographic and health characteristics were associated with having a CSOC based on face-to-face surveys at three time points in early childhood. Maternal low level of education was independently associated with a CSOC. Educated women may be more familiar than their counterparts with alternate sites of care, may have more resources to change sites, or may be more capable of changing practices if their needs are not met. We found that maternal nativity, but not race/ethnicity or language of survey, was independently associated with having a CSOC. Specifically, mothers who were born in the US were more likely to have a CSOC. The Western concept of continuity of care may seem obvious to those born in the US, but for those born elsewhere the emphasis on continuity may not be as strong. Qualitative studies assessing the views of US- versus foreign-born women on CSOC may help further our understanding of how culture impacts continuity of care.

Previous studies have linked maternal health services use with child health services use.

For example, women with poor prenatal care were less likely to have a continuous source of care for their children. ${ }^{30}$ We similarly found that women who had a postpartum check-up were more likely to have a continuous source of care. It is unknown whether this association reflects something about the mother's approach to healthcare or reflects information exchanged between the mother and her healthcare providers, or both. 
Having stable child health insurance was associated with having a CSOC. In today's healthcare environment, fluctuations in health insurance coverage by employers, changes in healthcare-system-insurer contracts, limitations on accepted insurances at healthcare provider offices, and changes in employment force some patients to involuntarily switch healthcare providers. Initiation of care at sites other than community-based health centers was associated with a higher likelihood of having a CSOC. Some families may view community-based health centers as temporary sites of care, as one study found that the majority of women left community-based health centers and went elsewhere for newborn care. ${ }^{36}$ In addition, care sites may vary in practice and philosophically on how CSOC is viewed.

Our study has several limitations. Our investigation was based on survey data; therefore, though we were able to comment on associations, we were unable to comment on cause and effect. CSOC was based on maternal report, and we did not validate whether or not the mothers actually took their children to the stated healthcare providers, or how often they were seen. The women in our study had familiarity with their child's healthcare provider and were able to give detailed contact information. Because we did not have data on the number of well-child care visits throughout the study period, we were not able to assess whether the children had "adequate well-child care." We determined use of parenting practices only by maternal report, which could have resulted in reporting bias; however, there is no reason to suspect that the reporting accuracy would differ for the comparison groups. Our use of self-reported parenting practices is consistent with previous, large-scale national studies as mentioned earlier. ${ }^{38,40,50}$ There may have been other confounding factors that were not measured in our study. Our participants were low-income, Philadelphia mothers who identified a healthcare provider for their child at all time points, and our findings may not be generalizable to other urban underserved communities. We 
may have underestimated the prevalence of "no CSOC" as those who did not complete all of the surveys were more likely to be foreign-born; and in our study, those who were foreign-born were less likely to have CSOC.

A major strength of this study is that we obtained information about each participant's source of care from longitudinal data. National surveys assessing usual source of care generally use cross-sectional data based on a single question asking if the child has a usual source of care. ${ }^{52,53}$ Other studies that use administrative data may be limited in that the physician listed may not be a physician known to the mother, and may not even be the physician who met directly with the mother. Our study looks at maternal responses that detail the practice name, location, and phone number at three time points to determine if the child actually had a CSOC. We had hypothesized that having a CSOC would be associated with an increased use of recommended parenting practices. This hypothesis was largely based on the idea that continuity of care implies a trusting and devotional relationship between the parent and a practice or provider. It may be that other influences -- such input from family members and friends, other health professionals, and public health messages on broadcast media -- play significant roles in the use of the parenting practices that we studied. For example, with infant sleep position, it is known that influencing factors other than physician recommendations include the presence of a grandmother in the household, observed practices of health professionals in the newborn nursery, and recommendations from non-physician sources. ${ }^{31,35,51,54,55}$ It may be that simply having a usual source of care, independent of being the same one or continuous, affects whether or not mothers use the parenting practices that we studied. For the low-income women in our sample, rates for breastfeeding 1 or more months and rates of reading were much lower than national 
rates. This warrants further investigation, and suggests the need for further intervention in this underserved population.

In summary, there are six major findings from our study of low-income women who access care for their children in the first two years of life: 1) maternal nativity, 2) maternal lowlevel of education, 3) stable child health insurance, 4) having a postpartum check-up, and 5) initiating child healthcare at a site other than a community-based health center were associated with a higher likelihood of having CSOC, and 6) use of parenting practices did not differ for those with and without a CSOC. 
We would like to thank all of the women who participated in this study, and all of the interviewers who collected the data.

306

307

308

309

310

311

312

313

314

315

316

317

318

319

320

321

322

323

324

325 


\section{REFERENCES}

1. Starfield S. Primary Care. Concept, Evaluation, and Policy. New York: Oxford University Press, Inc, 1992.

2. American Academy of Pediatrics. Medical Home Initiatives for Children with Special Needs Project Advisory Committee. The medical home. Pediatrics. Jul 2002;110(1 Pt 1):184-186.

3. American Academy of Pediatrics. Bright Futures: Guidelines for Health Supervision of Infants, Children, and Adolescents. 2nd Rev ed. Chicago: American Academy of Pediatrics, 2000.

4. Gartner LM, Morton J, Lawrence RA, et al. Breastfeeding and the use of human milk. Pediatrics. Feb 2005;115(2):496-506.

5. American Academy of Pediatrics. TIPP: The Injury Prevention Program: A Guide to Safe Counseling in Office Practice. http://www.aap.org/family/tippmain.htm. Accessed October 1, 2005.

6. Lambrew JM, DeFriese GH, Carey TS, Ricketts TC, Biddle AK. The effects of having a regular doctor on access to primary care. Med Care. Feb 1996;34(2):138-151.

7. Ettner SL. The relationship between continuity of care and the health behaviors of patients: does having a usual physician make a difference? Med Care. Jun 1999;37(6):547-555.

8. Bindman AB, Grumbach K, Osmond D, Vranizan K, Stewart AL. Primary care and receipt of preventive services. J Gen Intern Med. May 1996;11(5):269-276.

9. Fan VS, Burman M, McDonell MB, Fihn SD. Continuity of care and other determinants of patient satisfaction with primary care. J Gen Intern Med. Mar 2005;20(3):226-233. 
10. Bice TW, Boxerman SB. A quantitative measure of continuity of care. Med Care. Apr 1977;15(4):347-349.

11. Christakis DA, Wright JA, Koepsell TD, Emerson S, Connell FA. Is greater continuity of care associated with less emergency department utilization? Pediatrics. Apr 1999;103(4 Pt 1):738-742.

12. Brousseau DC, Meurer JR, Isenberg ML, Kuhn EM, Gorelick MH. Association between infant continuity of care and pediatric emergency department utilization. Pediatrics. Apr 2004;113(4):738-741.

13. Jee SH, Cabana MD. Indices for continuity of care: a systematic review of the literature. Med Care Res Rev. Apr 2006;63(2):158-188.

14. Merzel C, Moon-Howard J. Access to health services in an urban community: does source of care make a difference? J Urban Health. Jun 2002;79(2):186-199.

15. Bartman BA, Moy E, D'Angelo LJ. Access to ambulatory care for adolescents: the role of a usual source of care. J Health Care Poor Underserved. May 1997;8(2):214-226.

16. Hjortdahl P, Laerum E. Continuity of care in general practice: effect on patient satisfaction. Bmj. May 16 1992;304(6837):1287-1290.

17. Becker MH, Drachman RH, Kirscht JP. Continuity of pediatrician: new support for an old shibboleth. J Pediatr. Apr 1974;84(4):599-605.

18. Wasson JH, Sauvigne AE, Mogielnicki RP, et al. Continuity of outpatient medical care in elderly men. A randomized trial. Jama. Nov 2 1984;252(17):2413-2417.

19. Saultz JW, Albedaiwi W. Interpersonal continuity of care and patient satisfaction: a critical review. Ann Fam Med. Sep-Oct 2004;2(5):445-451. 
20. Christakis DA, Wright JA, Zimmerman FJ, Bassett AL, Connell FA. Continuity of care is associated with high-quality careby parental report. Pediatrics. Apr 2002;109(4):e54.

21. O'Malley AS, Forrest CB. Continuity of care and delivery of ambulatory services to children in community health clinics. J Community Health. Jun 1996;21(3):159-173.

22. Christakis DA, Mell L, Wright JA, Davis R, Connell FA. The association between greater continuity of care and timely measles-mumps-rubella vaccination. Am J Public Health. Jun 2000;90(6):962-965.

23. Joffe GP, Rodewald LE, Herbert T, Barth R, Szilagyi PG. Scattering of primary care: doctor switching and utilization of health care by children on fee-for-service Medicaid. $J$ Urban Health. Sep 1999;76(3):322-334.

24. Christakis DA, Mell L, Koepsell TD, Zimmerman FJ, Connell FA. Association of lower continuity of care with greater risk of emergency department use and hospitalization in children. Pediatrics. Mar 2001;107(3):524-529.

25. Gill JM, Mainous AG, 3rd, Nsereko M. The effect of continuity of care on emergency department use. Arch Fam Med. Apr 2000;9(4):333-338.

26. Gill JM, Mainous AG, 3rd. The role of provider continuity in preventing hospitalizations. Arch Fam Med. Jul-Aug 1998;7(4):352-357.

27. De Maeseneer JM, De Prins L, Gosset C, Heyerick J. Provider continuity in family medicine: does it make a difference for total health care costs? Ann Fam Med. Sep-Oct 2003;1(3):144-148.

28. Weiss LJ, Blustein J. Faithful patients: the effect of long-term physician-patient relationships on the costs and use of health care by older Americans. Am J Public Health. Dec 1996;86(12):1742-1747. 
29. Raddish M, Horn SD, Sharkey PD. Continuity of care: is it cost effective? Am J Manag Care. Jun 1999;5(6):727-734.

30. Mustard CA, Mayer T, Black C, Postl B. Continuity of pediatric ambulatory care in a universally insured population. Pediatrics. Dec 1996;98(6 Pt 1):1028-1034.

31. Willinger M, Ko CW, Hoffman HJ, Kessler RC, Corwin MJ. Factors associated with caregivers' choice of infant sleep position, 1994-1998: the National Infant Sleep Position Study. Jama. Apr 26 2000;283(16):2135-2142.

32. Kuo AA, Franke TM, Regalado M, Halfon N. Parent report of reading to young children. Pediatrics. Jun 2004;113(6 Suppl):1944-1951.

33. Labarere J, Gelbert-Baudino N, Ayral AS, et al. Efficacy of breastfeeding support provided by trained clinicians during an early, routine, preventive visit: a prospective, randomized, open trial of 226 mother-infant pairs. Pediatrics. Feb 2005;115(2):e139-146.

34. High PC, LaGasse L, Becker S, Ahlgren I, Gardner A. Literacy promotion in primary care pediatrics: can we make a difference? Pediatrics. Apr 2000;105(4 Pt 2):927-934.

35. Colson ER, Bergman DM, Shapiro E, Leventhal JH. Position for newborn sleep: associations with parents' perceptions of their nursery experience. Birth. Dec $2001 ; 28(4): 249-253$.

36. Chung EK, McCollum KF, Elo IT, Culhane JF. Does prenatal care at community-based health centers result in infant primary care at these sites? Ambul Pediatr. Jan-Feb 2006;6(1):25-31.

37. Chung EK, McCollum KF, Elo IT, Lee HJ, Culhane JF. Maternal depressive symptoms and infant health practices among low-income women. Pediatrics. Jun 2004;113(6):e523529. 
38. Progress in reducing risky infant sleeping positions--13 states, 1996-1997. MMWR Morb Mortal Wkly Rep. Oct 8 1999;48(39):878-882.

39. National Center for Education Statistics. National Household Education Surveys Program. http://nces.ed.gov/nhes/questionnaires.asp. Accessed October 13, 2005.

40. National Center for Education Statistics. Home literacy activities and signs of children's emerging literacy, 1993 and 1999.:NCES Publication No. 2000-2026rev:2001-2016.

41. Brent RL, Weitzman M. The pediatrician's role and responsibility in educating parents about environmental risks. Pediatrics. Apr 2004;113(4 Suppl):1167-1172.

42. Oddy WH. The impact of breastmilk on infant and child health. Breastfeed Rev. Nov 2002;10(3):5-18.

43. Stein MT, Perrin EL. Guidance for effective discipline. American Academy of Pediatrics. Committee on Psychosocial Aspects of Child and Family Health. Pediatrics. Apr 1998;101(4 Pt 1):723-728.

44. American Academy of Pediatrics. Task Force on Infant Sleep Position and Sudden Infant Death Syndrome. Changing concepts of sudden infant death syndrome: implications for infant sleeping environment and sleep position. Pediatrics. Mar 2000;105(3 Pt 1):650656.

45. Gardner HG. Office-based counseling for unintentional injury prevention. Pediatrics. Jan 2007;119(1):202-206.

46. Fargason CA, Jr., Chernoff RG, Socolar RR. Attitudes of academic pediatricians with a specific interest in child abuse toward the spanking of children. Arch Pediatr Adolesc Med. Oct 1996;150(10):1049-1053. 
47. Stata Corporation. Stata Statistical Software: Release 6.0. College Station, TX: Stata Corporation, 1999.

48. Lemeshow S, Hosmer DW, Jr. A review of goodness of fit statistics for use in the development of logistic regression models. Am J Epidemiol. Jan 1982;115(1):92-106.

49. March of Dimes Perinatal Data Center.

http://www.marchofdimes.com/professionals/680_1239.asp. Accessed October 13, 2005.

50. Li R, Darling N, Maurice E, Barker L, Grummer-Strawn LM. Breastfeeding rates in the United States by characteristics of the child, mother, or family: the 2002 National Immunization Survey. Pediatrics. Jan 2005;115(1):e31-37.

51. Phares TM, Morrow B, Lansky A, et al. Surveillance for disparities in maternal healthrelated behaviors--selected states, Pregnancy Risk Assessment Monitoring System (PRAMS), 2000-2001. MMWR Surveill Summ. Jul 2 2004;53(4):1-13.

52. Inkelas M, Schuster MA, Olson LM, Park CH, Halfon N. Continuity of primary care clinician in early childhood. Pediatrics. Jun 2004;113(6 Suppl):1917-1925.

53. Newacheck PW, Stoddard JJ, Hughes DC, Pearl M. Health insurance and access to primary care for children. $N$ Engl J Med. Feb 19 1998;338(8):513-519.

54. Brenner RA, Simons-Morton BG, Bhaskar B, et al. Prevalence and predictors of the prone sleep position among inner-city infants. Jama. Jul 22-29 1998;280(4):341-346.

55. Chung EK, Hung YY, Marchi K, Chavez GF, Braveman P. Infant sleep position: associated maternal and infant factors. Ambul Pediatr. Sep-Oct 2003;3(5):234-239. 
Figure 1. Flow Diagram of Study Participants

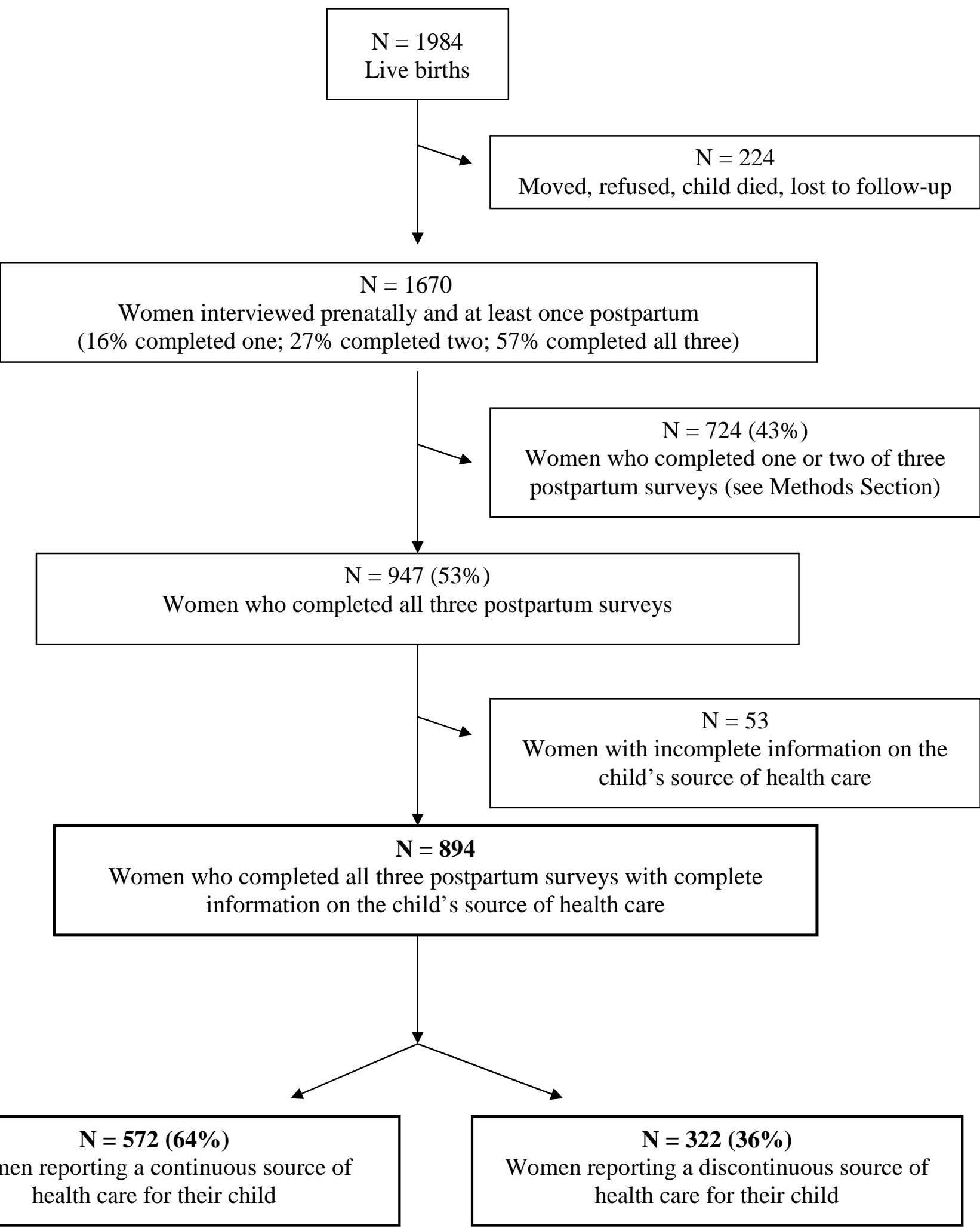


Table 1. Sociodemographic and Health Characteristics for the Overall Study Population, and a Comparison of Those with and without a Continuous Source of Care (CSOC).

\begin{tabular}{|c|c|c|c|c|}
\hline Maternal Characteristics & $\begin{array}{l}\text { Overall Study } \\
\text { Population } \\
(\mathbf{N}=\mathbf{8 9 4})\end{array}$ & $\begin{array}{c}\text { CSOC } \\
(\mathrm{N}=572)\end{array}$ & $\begin{array}{l}\text { No CSOC } \\
(\mathbf{N}=322)\end{array}$ & $\begin{array}{c}\text { CSOC versus No } \\
\text { CSOC } \\
\text { P-value }\end{array}$ \\
\hline Mean maternal age $( \pm S D)^{1}$, years & $24 \pm 6$ & $24 \pm 6$ & $24 \pm 6$ & NS \\
\hline $\begin{array}{l}\text { Education }^{1}, \% \\
\text { Less than high school } \\
\text { High school/GED } \\
\text { College or more }\end{array}$ & $\begin{array}{l}39 \\
43 \\
17\end{array}$ & $\begin{array}{l}39 \\
46 \\
14\end{array}$ & $\begin{array}{l}39 \\
38 \\
23\end{array}$ & 0.003 \\
\hline $\begin{array}{l}\text { Race/Ethnicity }{ }^{1} \% \\
\text { African American } \\
\text { Latina } \\
\text { White } \\
\text { Other }\end{array}$ & $\begin{array}{c}71 \\
15 \\
10 \\
3\end{array}$ & $\begin{array}{c}71 \\
16 \\
10 \\
3\end{array}$ & $\begin{array}{c}72 \\
15 \\
10 \\
3\end{array}$ & NS \\
\hline $\begin{array}{l}\text { Prenatal care at Spanish-speaking } \\
\text { site }^{1}\end{array}$ & 14 & 15 & 12 & NS \\
\hline Language of survey in Spanish ${ }^{1}$ & 6 & 6 & 6 & NS \\
\hline Nativity $^{1}$, US born, $\%$ & 81 & 83 & 77 & 0.015 \\
\hline Marital status ${ }^{1}$ : single, $\%$ & 76 & 77 & 75 & NS \\
\hline $\begin{array}{l}\text { Annual household income }{ }^{1}, \% \\
\quad<\$ 2,150 \\
\$ 2,150-\$ 6,191 \\
\$ 6,192-\$ 11,609 \\
>\$ 11,609\end{array}$ & $\begin{array}{l}24 \\
24 \\
26 \\
26\end{array}$ & $\begin{array}{l}24 \\
23 \\
27 \\
26\end{array}$ & $\begin{array}{l}25 \\
25 \\
23 \\
27\end{array}$ & NS \\
\hline Uninsured $^{1}, \%$ & 59 & 60 & 57 & NS \\
\hline Stable residence ${ }^{4}, \%$ & 48 & 52 & 46 & NS \\
\hline $\operatorname{Car}^{\operatorname{access}^{2}, \%}$ & 91 & 92 & 90 & NS \\
\hline
\end{tabular}

SD: standard deviation; GED: General Educational Development credential

${ }^{1}$ At antepartum visit.

${ }^{2}$ At PP1. 


\begin{tabular}{|c|c|c|c|c|}
\hline $\begin{array}{l}\text { Had a usual source of pre- } \\
\text { pregnancy care }^{2}, \%\end{array}$ & 62 & 63 & 61 & NS \\
\hline High risk pregnancy ${ }^{2}, \%$ & 27 & 27 & 26 & NS \\
\hline Had a postpartum check-up ${ }^{2}, \%$ & 87 & 89 & 84 & $\mathbf{0 . 0 2 4}$ \\
\hline $\begin{array}{l}\text { Had a main prenatal care } \\
\text { provider }^{2}, \%\end{array}$ & 40 & 39 & 41 & NS \\
\hline \multicolumn{5}{|l|}{ Child Characteristics } \\
\hline $\begin{array}{l}\mathrm{Age}^{3} \text {, months } \\
\quad<23.5 \\
23.6-26.1 \\
>26.1\end{array}$ & $\begin{array}{l}24 \\
51 \\
25\end{array}$ & $\begin{array}{l}23 \\
53 \\
24\end{array}$ & $\begin{array}{l}26 \\
47 \\
27\end{array}$ & NS \\
\hline $\begin{array}{l}\text { Birth order }{ }^{1} \\
\text { First } \\
\text { Second } \\
\text { Third or more }\end{array}$ & $\begin{array}{l}50 \\
27 \\
23\end{array}$ & $\begin{array}{l}49 \\
28 \\
23\end{array}$ & $\begin{array}{l}52 \\
25 \\
24\end{array}$ & NS \\
\hline Gender $^{5}:$ male, $\%$ & 51 & 49 & 53 & NS \\
\hline $\begin{array}{l}\text { Low birthweight }{ }^{5}(<2500 \text { grams }) \text {, } \\
\%\end{array}$ & 10 & 10 & 11 & NS \\
\hline $\begin{array}{l}\text { Preterm } \text { birth }^{5}(<37 \mathrm{wks} \\
\text { gestation), \% }\end{array}$ & 11 & 11 & 12 & NS \\
\hline Has special needs ${ }^{2}, \%$ & 10 & 9 & 12 & NS \\
\hline Stable child health insurance ${ }^{4}, \%$ & 74 & 80 & 65 & $<0.001$ \\
\hline $\begin{array}{l}\text { Initial site of hospitalization }{ }^{2} \text { : } \\
\text { intensive care nursery, } \%\end{array}$ & 14 & 13 & 15 & NS \\
\hline \multicolumn{5}{|l|}{$\begin{array}{l}\text { Site of initial well-child care }{ }^{2}, \% \\
\text { Private practice }\end{array}$} \\
\hline $\begin{array}{l}\text { Hospital-based clinic } \\
\text { Community-based health } \\
\text { center }\end{array}$ & $\begin{array}{l}29 \\
33 \\
37\end{array}$ & $\begin{array}{l}33 \\
36 \\
31\end{array}$ & $\begin{array}{l}24 \\
28 \\
48\end{array}$ & $<0.001$ \\
\hline
\end{tabular}

${ }^{3}$ At PP3.

4 Based on PP1, 2 , and 3.

${ }^{5}$ Linked birth certificate data. 
Table 2. Prevalence Rates of Recommended Parenting Practices Among Overall Study Participants, Those with CSOC and Those without CSOC.

\begin{tabular}{|llcccc|}
\hline & Parenting Practice & $\begin{array}{c}\text { Overall } \\
\text { Percent } \\
\text { At 2-4 months }\end{array}$ & $\begin{array}{c}\text { CSOC } \\
\text { Percent } \\
\text { (N= 894) }\end{array}$ & $\begin{array}{c}\text { No CSOC } \\
\text { Percent }\end{array}$ & P-value* \\
& Breastfeeding for $\geq 1$ month & 26 & 24 & 28 & NS \\
& Use of back sleep position & 54 & 54 & 54 & NS \\
At 10-12 months & Reading $\geq 3$ times/week & 57 & 57 & 57 & NS \\
& Not using corporal & 86 & 87 & 85 & NS \\
& punishment & & & & \\
At 22-26 months & Use of stair gates & & 21 & 24 & NS \\
& Use of electric outlet covers & 57 & 56 & 58 & NS \\
\hline
\end{tabular}

*Based on Chi-square testing to assess for group differences between those with CSOC and those without CSOC. 
Table 3. Logistic Regression Estimates (Odds Ratios) ${ }^{1}$ of Maternal and Infant Characteristics Associated with a Continuous Source of Care (CSOC), N = 894

\begin{tabular}{|c|c|}
\hline Characteristic & $\begin{array}{c}\text { Adjusted Odds Ratio for CSOC } \\
\text { (95\% Confidence Interval) }\end{array}$ \\
\hline $\begin{array}{l}\text { Education } \\
\text { Less than high school } \\
\text { High school/GED } \\
\text { College or more }\end{array}$ & $\begin{array}{c}1.66(1.06,2.60) \\
1.80(1.18,2.74) \\
1.00\end{array}$ \\
\hline $\begin{array}{l}\text { Maternal race/ethnicity } \\
\text { African American } \\
\text { Latina } \\
\text { White } \\
\text { Other }\end{array}$ & $\begin{array}{c}1.23(0.73,2.09) \\
1.77(0.88,3.54) \\
1.00 \\
2.25(0.82,6.09)\end{array}$ \\
\hline $\begin{array}{l}\text { Maternal nativity } \\
\text { US-born } \\
\text { Foreign-born }\end{array}$ & $\begin{array}{c}1.69(1.06,2.70) \\
1.00\end{array}$ \\
\hline $\begin{array}{l}\text { Language of survey } \\
\text { Spanish } \\
\text { English }\end{array}$ & $\begin{array}{c}1.47(0.65,3.33) \\
1.00\end{array}$ \\
\hline $\begin{array}{l}\text { Had postpartum check-up } \\
\text { Yes } \\
\text { No }\end{array}$ & $\begin{array}{c}1.74(1.12,2.70) \\
1.00\end{array}$ \\
\hline $\begin{array}{l}\text { Child health insurance during study period } \\
\text { Stable } \\
\text { Changed }\end{array}$ & $\begin{array}{c}\mathbf{2 . 0 3}(\mathbf{1 . 4 5}, \mathbf{2 . 8 5}) \\
1.00\end{array}$ \\
\hline $\begin{array}{l}\text { Site of initial well-child care } \\
\text { Private practice } \\
\text { Hospital-based clinic } \\
\text { Community-based health center }\end{array}$ & $\begin{array}{c}2.44(1.65,3.60) \\
2.03(1.43,2.88) \\
1.00\end{array}$ \\
\hline
\end{tabular}

Statistically significant findings are in bold font.

\footnotetext{
${ }^{1}$ In addition to those shown, we adjusted for the following variables that were not statistically significant: maternal age, marital status, residence stability, car access, and child birth order and age at PP3.
} 